\title{
Tumor cell lysate induces the immunosuppression and apoptosis of mouse immunocytes
}

\author{
BOHAN DONG ${ }^{1}$, GUANGLI DAI ${ }^{2}$, LEI XU ${ }^{1}$, YAO ZHANG ${ }^{1}$, LIEFENG LING $^{1}$, LINGLING SUN $^{1}$ and JUN LV ${ }^{1}$ \\ ${ }^{1}$ Department of Biochemistry, Wannan Medical College, Wuhu, Anhui 241002; ${ }^{2}$ Department of Gynaecology and Obstetrics, \\ Traditional Chinese Medical Hospital of Wuhu, Wuhu, Anhui 241000, P.R. China
}

Received February 2, 2014; Accepted June 10, 2014

DOI: $10.3892 / \mathrm{mmr} .2014 .2606$

\begin{abstract}
Although tumor cell lysate (TCL) is a type of immunocyte stimulator, its immunosuppressive function must not be ignored. The present study reported that TCL prepared from a Lewis lung cancer cell was able to induce the development of immunosuppressive macrophages (MФ) and tolerogenic dendritic cells. In addition, TCL upregulated the expression of CD69 in mouse splenocytes, and cell apoptosis and the percentage of regulatory $T$ cells in mouse splenocytes simultaneously increased. Furthermore, the present study found that the immunosuppressive factor, hyaluronan, and the apoptosis inducers, Fas ligand and transforming growth factor- $\beta$, are present in TCL. These components may be associated with the emergence of immunosuppressive cells or splenocyte apoptosis. Thus, the present study has enriched our understanding of the composition of TCL and its negative regulatory effect on immunocytes.
\end{abstract}

\section{Introduction}

Tumor cell lysate (TCL) refers to the tumor lysate mixture that results following the artificial lysis of tumor cells. This mixture has multiple tumor antigens and thus possesses the ability to induce the activation of antitumor cells. However, TCL has a dual effect on immune cells. TCL not only activates these immune cells, but may also induce immunosuppression. For patients with myeloma that receive treatment with an autologous dendritic cell (DC) vaccine, DCs should be incubated with the TCL derived from myeloma in vitro. During this incubation, TCL may induce a subset of DCs with stimulatory activity, while having the ability to induce immunotolerance in another subset of DCs (1). However, a transfusion of this

Correspondence to: Dr Bohan Dong, Department of Biochemistry, Wannan Medical College, 22 Wenchang West Road, Wuhu, Anhui 241002, P.R. China

E-mail: dongbohan2014@yeah.net

Key words: tumor cell lysate, anti-tumor vaccine, immunosuppressive cells, immunocyte apoptosis, lung cancer, mouse immunocytes subset of DCs may attenuate the specific immune response of effector $\mathrm{T}$ cells to tumor-associated antigens, resulting in antigen-specific immunotolerance of $\mathrm{T}$ cells and subsequently a low tumor response rate and short survival time (1). In a previous study, a TCL derived from Lewis lung cancer cells, in combination with mycobacterial heat shock protein 65 (MHSP65), was used to prepare MHSP65-TCL, which was found to activate the immune cells of mice during the early phase of immunization and was characterized by an upregulation of CD69 expression. However, during the late phase, the immune cell response to the vaccine decreased, accompanied by a reduction in the expression levels of CD69 (2).

The dual effects of TCL are ascribed to the different characteristics of the lysate components. As a complex mixture, TCL contains not only antigens, but also other substances that inhibit the immune cells or even induce cell apoptosis. Hyaluronan (HA) is a component of the extracellular matrix and can be secreted by nine types of cancer cells, including human lung cancer 95D cells and liver cancer HepG2 cells. The HA secreted by these cells may induce the production of immunosuppressive monocyte/macrophages (MФ) and DCs in vitro (3). Although these cells are in an active state, they may induce the apoptosis of T lymphocytes, while they, themselves, are also susceptible to apoptosis (4). In addition to the inhibitory effect on immune cells, certain proteins secreted by cancer cells may directly induce cell apoptosis. Fas ligand (Fas-L) and transforming growth factor- $\beta$ (TGF- $\beta$ ) are proteins that are closely associated with the apoptosis of immune cells and are potentially localized in the TCL. Fas-L can bind to Fas on immune cells to induce the activation of caspase in immune cells and to further induce cell apoptosis (5). However, TGF- $\beta$ may act on the TGF- $\beta$ receptor to activate the extracellular signal-regulated kinase/mitogen-activated protein kinase signaling pathway resulting in the apoptosis of immune cells (6). In addition, immunohistochemistry and western blotting demonstrated that the two proteins were expressed in the cancer cells. Western blot analysis demonstrated that Fas-L is expressed in 16 human lung cancer cell lines. In addition, immunohistochemistry results have demonstrated the expression of Fas-L in 23 out of 28 types of resected lung cancer (7). Furthermore, breast cancer cells also express Fas-L and lymphocyte apoptosis has been observed in adjacent normal tissues surrounding breast cancer tissues (8). Immunohistochemistry results have also revealed that the 
expression of TGF- $\beta$ was at a high level in 45 lung cancer samples (9). Patients with high TGF- $\beta$ expression levels in lung cancer cells were found to have a significantly shorter survival time following surgery (10). Immunohistochemistry and western blot assays enable the detection of intracellular proteins and thus, it was hypothesized that the TCL prepared from cancer cells may contain Fas-L and TGF- $\beta$.

On the basis of the aforementioned findings, the present study was undertaken to determine the concentration of HA, pro-apoptotic Fas-L and TGF- $\beta$ in the TCL from Lewis cells, and to further investigate whether TCL induces the production of immunosuppressive cells and the apoptosis of immune cells through these proteins.

\section{Materials and methods}

Mice and cell lines. Female C57BL/6 mice were purchased from Nanjing Qinglong Mountain Laboratory Animal Co., Ltd. (Nanjing, China) and maintained in microisolator cages under pathogen-free conditions. All mice were studied at 6-8 weeks of age. Experimental manipulation of the mice was undertaken in accordance with the National Institute of Health Guide for the Care and Use of Laboratory Animals (Bethesda, MA, USA). A mouse Lewis lung cancer cell line was purchased from the American Type Culture Collection (Manassas, VA, USA) and maintained in high-glucose Dulbecco's modified Eagle's medium (Wuhan Boshide Biotechnology Co., Wuhan, China) supplemented with $10 \%$ fetal calf serum (FCS; Invitrogen Life Technologies, Carlsbad, CA, USA), 100 U/ml penicillin and $100 \mu \mathrm{g} / \mathrm{ml}$ streptomycin (Sigma-Aldrich, St. Louis, MO, USA). This study was approved by the Ethics Committee of Wannan Medical College (Wuhu, China).

Preparation of TCL. To prepare the TCL, cultured Lewis cells were lysed using a freezing-thawing cycle in a $0.85 \%$ $\mathrm{NaCl}$ solution. This was repeated five times in rapid succession, between $-70^{\circ} \mathrm{C}$ and $37^{\circ} \mathrm{C}$ and then refrozen and stored in a $-70^{\circ} \mathrm{C}$ refrigerator until use. Each of the TCLs were detected under a microscope (Olympus Corporation, Tokyo, Japan) using trypan blue staining (Sigma-Aldrich, St. Louis, MO, USA) following the final thawing.

Isolation of monocytes and culture of DCs. Peritoneal MФs were isolated using plastic adhesion and further subset purification was performed with magnetic beads (Miltenyi Biotech, Bergisch, Gladbach, Germany) and specific biotin-conjugated antibodies (BD Biosciences, Franklin Lakes, NJ, USA), yielding $>98 \%$ cell purity. Subsequently, MФ $\left(1 \times 10^{6}\right.$ cells $\left./ \mathrm{ml}\right)$ were cultured in DMEM medium (Wuhan Boshide Biotechnology Co., Wuhan, China) with $10 \% \mathrm{FBS}$ and added to either $0.85 \% \mathrm{NaCl}$ or a TCL prepared from $1 \times 10^{6}$ Lewis cells for $72 \mathrm{~h}$. The culture supernatant was collected every $24 \mathrm{~h}$. To prepare murine DCs, bone marrow cells were harvested from the tibiae and femurs of the C57/BL6 mice and depleted of red blood cells using a red blood cell lysis buffer (Sigma-Aldrich). Bone marrow cells were cultured in an RPMI-1640 medium containing $10 \% \mathrm{FBS}, 100 \mathrm{U} / \mathrm{ml}$ penicillin, $100 \mu \mathrm{g} / \mathrm{ml}$ streptomycin and $50 \mu \mathrm{M} 2$-mercaptoethanol (Invitrogen Life Technologies), supplemented with $20 \mathrm{ng} / \mathrm{ml}$ murine granulocy te-macrophage colony-stimulating factor (GM-CSF) and IL-4 (Miltenyi Biotech) in the presence of $\mathrm{NaCl}$ or a TCL prepared from Lewis cells $\left(1 \times 10^{6}\right)$. On days 3 and 6, the culture medium was replaced with a fresh medium supplemented with GM-CSF. From day 5, the culture supernatant was collected every $24 \mathrm{~h}$.

Flow cytometric analysis. The mouse spleen cells $\left(1 \times 10^{6} / \mathrm{ml}\right)$ that were co-cultured with either TCL prepared from Lewis lung cancer cells $\left(1 \times 10^{6}\right)$ or $0.85 \% \mathrm{NaCl}$ for $48 \mathrm{~h}$ were collected, washed and resuspended in phosphate buffered-saline (PBS) supplemented with $1 \%$ heat-inactivated fetal bovine serum. Thereafter, the mouse spleen cells were stained with Annexin V and propidium iodide (BD Pharmingen, San Diego, CA, USA) to detect apoptosis or stained with fluorescein isothiocyanate-labeled anti-CD4 and phycoerythrin-labeled anti-CD25 monoclonal antibodies (mAB; BD Pharmingen) to analyze the activation of regulatory $\mathrm{T}$ (Treg) cells. The cells were then put on ice in the dark for $30 \mathrm{~min}$, washed with a fluorescence-activated cell sorting buffer (1X PBS) and analyzed by flow cytometry (FACS Calibur; Becton-Dickinson, San Jose, CA, USA).

Western blot analysis. The TCL was prepared from Lewis cells $\left(1 \times 10^{6}\right)$ and was then separated using SDS-PAGE. The protein was transferred on gel onto a nitrocellulose membrane. The membrane was incubated with an anti-mFas-L mAb (Wuhan Boshide Biotechnology Co.) and an anti-rabbit polyclonal IgG-horseradish peroxidase successively (Wuhan Boshide Biotechnology Co.). To detect the membrane protein, $0.01 \mathrm{~g} \mathrm{3,3'-diaminobenzidine} \mathrm{(Sigma)} \mathrm{was} \mathrm{dissolved} \mathrm{in} 10 \mathrm{ml}$ of $1 \mathrm{X}$ PBS with $0.25 \mathrm{~g} \mathrm{NiSO}_{4}$ and $15 \% \mathrm{H}_{2} \mathrm{O}_{2}(1.5 \mu \mathrm{l})$.

DNA ladder. The spleen cells $\left(1 \times 10^{6}\right)$ were treated with TCL that was prepared from either Lewis lung cancer cells $\left(1 \times 10^{6}\right)$ or $0.85 \% \mathrm{NaCl}$ for $48 \mathrm{~h}$ and were then collected and washed twice with PBS. The splenocyte DNA was extracted using the Genomic DNA Mini Preparation kit with Spin Column (Beyotime Institute of Biotechnology, Haimen, China). Subsequently, $\sim 15 \mu \mathrm{g}$ DNA was loaded onto a 1.5\% agarose gel and analyzed using electrophoresis. The gel was stained with ethidium bromide and visualized under ultraviolet light.

ELISA. Concentrations of tumor necrosis factor- $\alpha$ (TNF- $\alpha$ ), interleukin (IL)-10, HA and TGF- $\beta$ were determined using ELISA kits (Wuhan Boshide Biotechnology Co.).

Statistical analysis. In the present study, the data on cytokine concentrations and surface marker expression are presented as the mean \pm standard deviation. Statistical significance was determined using Student's t-test. $\mathrm{P}<0.05$ was considered to indicate a statistically significant difference.

\section{Results}

HA in TCL from Lewis cells induces the production of immunosuppressive $M \Phi$ and DCs in mice. HA is a matrix required for the growth of cancer cells. HA is secreted by cancer cells and may induce the production of immunosuppressive cells, resulting in the inability of immune cells to kill cancer cells (11-13). Certain cells can synthesize HA, including liver 
A

$\mathrm{NaCl} \quad 10 \mathrm{mg} / \mathrm{ml} \quad 20 \mathrm{mg} / \mathrm{ml} \quad 40 \mathrm{mg} / \mathrm{ml} \quad 80 \mathrm{mg} / \mathrm{ml} \quad 160 \mathrm{mg} / \mathrm{ml} \quad \mathrm{TCL}$

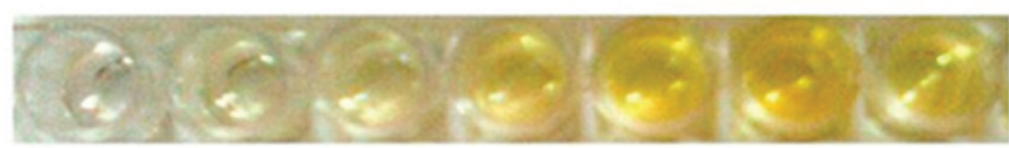

B
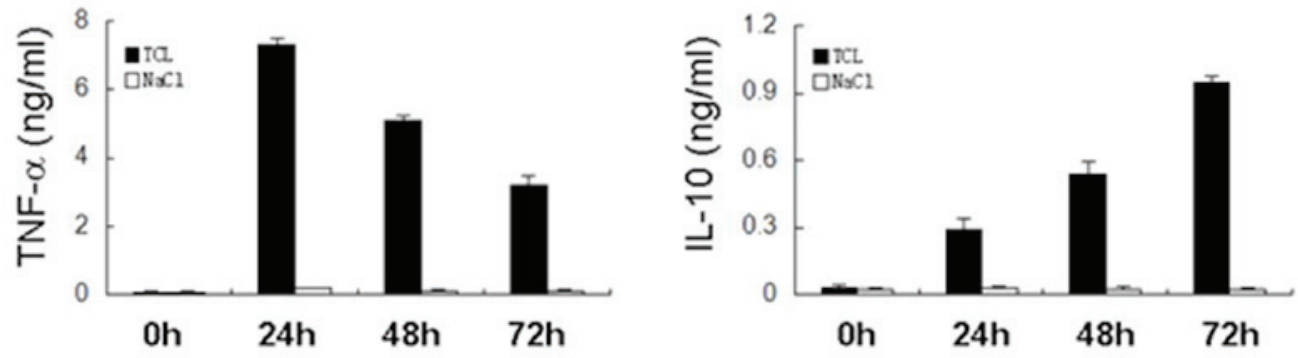

C
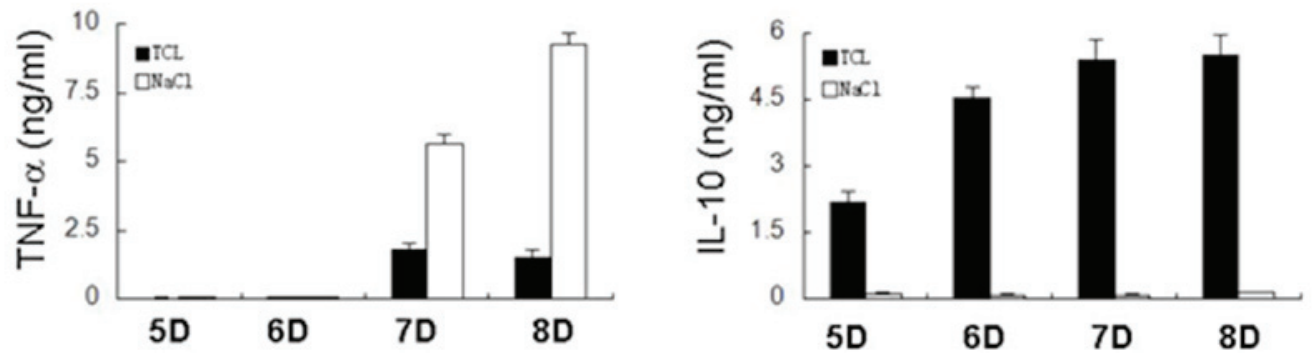

Figure 1. TCL induces the development of immunosuppressive macrophages and dendritic cells. (A) Lewis lung cancer cells $\left(1 \times 10^{6}\right)$ were used to produce TCL. The HA in TCL was detected by ELISA and the concentration of HA was calculated by comparing the actual OD value of TCL to that of different HA standard samples. The actual OD value of TCL was: TCL (well 7) OD - NaCl (well 1) OD. The actual OD of the standard sample was: HA standard samples (wells 2-6) OD - Blank well OD. (B) Mouse monocytes were cultured for 3 days in a medium containing $0.85 \% \mathrm{NaCl}$ (white bars) or with TCL from Lewis lung cancer cells (black bars). The production of the TNF- $\alpha$ and IL-10 cytokines was determined by ELISA. (C) Purified mouse DCs were cultured for 6 days with granulocyte-macrophage colony-stimulating factor and IL-4 in a medium containing $0.85 \% \mathrm{NaCl}$ (white bars) or with TCL from Lewis lung cancer cells (black bars). Thereafter, the DCs were stimulated with lipopolysaccharide for $24 \mathrm{~h}$ and the production of the TNF- $\alpha$ and IL-10 cytokines was determined by ELISA. The data regarding cytokine production are presented as the mean \pm standard deviation of three experiments. TLC, tumor cell lysate; HA, hyaluronan; OD, optical density; $\mathrm{NaCl}$, sodium chloride; IL, interleukin; TNF- $\alpha$, tumor necrosis factor- $\alpha$.

cancer HepG2 cells, cervical cancer HeLa cells and lung cancer 95D cells (3). To investigate whether HA is present in the TCL of mouse Lewis lung cancer cells, Lewis cells were subjected to repeated freezing and thawing to prepare the TCL. ELISA was then performed to detect HA in the TCL. The results demonstrated the presence of mouse-derived HA in the TCL. Following comparison of HA in the TCL with standard HA, the concentration of HA in the TCL was $42 \mathrm{mg} / \mathrm{ml}$ in the Lewis lung cancer cells $\left(1 \times 10^{6}\right.$; Fig. 1A). In our previous study, the mice were immunized at four time points. Thus, the concentration of accumulated HA may be $>42 \mathrm{mg} / \mathrm{ml}$ in vivo (2). HA may induce the production of immunosuppressive MФs and DCs. Following the detection of HA in the TCL, whether TCL could induce the production of these immunosuppressive cells was further investigated. TCL from the Lewis cells was used to treat mouse MФs and DCs independently and then the levels of TNF- $\alpha$ and IL-10 secreted by the MФs and DCs were detected. As shown in Fig. 1B, after $24 \mathrm{~h}$ treatment with TCL, the concentrations of TNF- $\alpha$ and IL-10 secreted by the MФs were markedly increased. The concentration of TNF- $\alpha$ from the MФs began to decrease at $48 \mathrm{~h}$. However, the concentration of IL-10 continuously increased and remained at a high level at $72 \mathrm{~h}$. Overall, following incubation with the TCL, the mouse MФs had an increased secretion of TNF- $\alpha$ during the early phase that continuously decreased thereafter. However, IL-10 secreted by the mouse MФs continuously increased. Following $\mathrm{NaCl}$ treatment, the quantity of TNF- $\alpha$ and IL-10 from the MФs remained stable at 24, 48 and $72 \mathrm{~h}$. At four time points, the TNF- $\alpha$ concentration was $0.067,0.174,0.116$ and $0.117 \mathrm{pg} / \mathrm{ml}$, respectively ( $\mathrm{P}<0.01 \mathrm{vs}$. TCL group). The IL-10 concentration was $0.022,0.029,0.025$ and $0.023 \mathrm{pg} / \mathrm{ml}$, respectively ( $\mathrm{P}<0.01 \mathrm{vs.} \mathrm{TCL}$ group).

As with the mouse MФs, the expression levels of IL-10 gradually increased in the immature mouse DCs after 6 days 
A

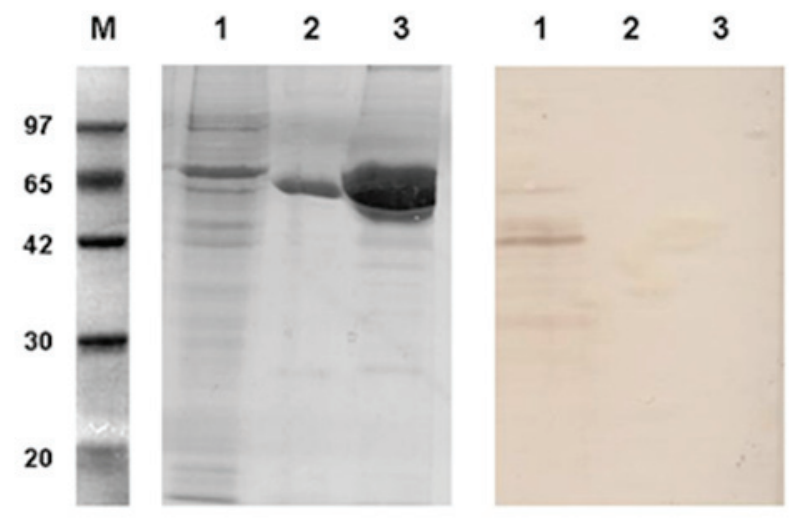

B
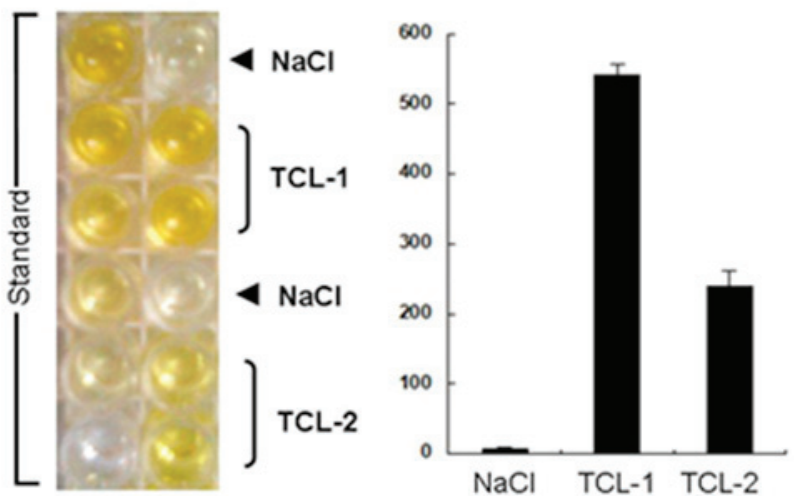

Figure 2. Fas-L and TGF- $\beta$ expression in TCL. (A) TCL was prepared from $1 \times 10^{6}$ Lewis lung cancer cells. Immunoblot analysis was processed to detect the Fas-L in TCL with anti-Fas-L antibody. FasL (Lane 1 of NC membrane) was detected in the TCL, but bovine serum albumin (Lane 2 of NC membrane) and mycobacterial heat shock protein 65 (Lane 3 of NC membrane) control proteins were not detected. (B) TCL was produced from $1 \times 10^{6}$ or $2 \times 10^{6}$ Lewis lung cancer cells. ELISA was processed to detect the TGF- $\beta$ in TCL and the concentration of HA was calculated by comparing the actual OD value of TCL to that of different HA standard samples. The actual OD value of TCL was: TCL OD (TCL-1 or TCL-2 well) - NaCl OD. The actual OD of the standard sample was: HA standard samples OD - Blank well OD. TCL-1 indicates TCL from $2 \times 10^{6}$ Lewis lung cancer cells. TCL-2 signifies TCL from 1x10 $10^{6}$ Lewis lung cancer cells. NC, nitrocellulose; Fas-L, Fas ligand; TGF- $\beta$, transforming growth factor- $\beta$; TCL, tumor cell lysate; HA, hyaluronan; OD, optical density; NaCl, sodium chloride; M, marker.

incubation with TCL in vitro (Fig. 1C). On day 5, the DCs remained immature and IL-10 secretion began to increase. When these cells had become completely mature on day 6 , the IL-10 secretion continuously increased on days 7 and 8 . By contrast, the secretion of IL-10 in the mouse DCs remained unaltered following $\mathrm{NaCl}$ treatment regardless of the maturation of the DCs. However, when NaCl-treated DCs had become mature, lipopolysaccharide (LPS) could stimulate the excessive secretion of TNF- $\alpha$ by mature DCs. Following a 24 (day 7) and $48 \mathrm{~h}$ (day 8) treatment with LPS, the TNF- $\alpha$ concentration was 5.655 and $9.255 \mathrm{ng} / \mathrm{ml}$, respectively. In addition, the TCL-treated DCs were insensitive to LPS. After a 24 (day 7) and $48 \mathrm{~h}$ (day 8) treatment with LPS, the TNF- $\alpha$ concentration was 1.790 and $1.515 \mathrm{pg} / \mathrm{ml}$, respectively $(\mathrm{P}<0.01$ vs $\mathrm{NaCl}$ control).

Fas- $L$ and TGF- $\beta$ in TCL from Lewis cells induces the apoptosis of mouse lymphocytes. Cancer cells may induce the apoptosis of immune cells by secreting pro-apoptotic factors
(Fas-L and TGF- $\beta$ ), which is one of mechanisms underlying the escape of cancer cells from antitumor immunity (14-19). In the present study, western blot analysis and ELISA were performed to detect Fas-L and TGF- $\beta$ in the TCL from Lewis lung cancer cells (Fig. 2A). Western blot analysis demonstrated that the Fas-L concentration was $200 \mathrm{ng} / \mathrm{ml}$ in the TCL from the Lewis cells $\left(1 \times 10^{6}\right)$ and that the Fas-L detected by the western blot assay had a high specificity and could not react with non-specific proteins (including MHSP65 and bovine serum albumin). ELISA demonstrated that the TGF- $\beta$ concentration was $239.64 \mathrm{pg} / \mathrm{ml}$ in the TCL from the Lewis cells $\left(1 \times 10^{6}\right)$. However, no TGF- $\beta$ was identified in the TCL from the Lewis cells in the $\mathrm{NaCl}$ group (Fig. 2B).

Subsequently, the mouse splenocytes were incubated with the TCL for $48 \mathrm{~h}$ in vitro. The results demonstrated that TCL was able to markedly stimulate the apoptosis of mouse splenocytes (Fig. 3A). When compared with the $\mathrm{NaCl}$ group, the apoptotic rate was as high as $34.82 \%(\mathrm{P}<0.05)$. In addition, the apoptotic rate of the mouse splenocytes decreased to $0.55 \%$ 
A

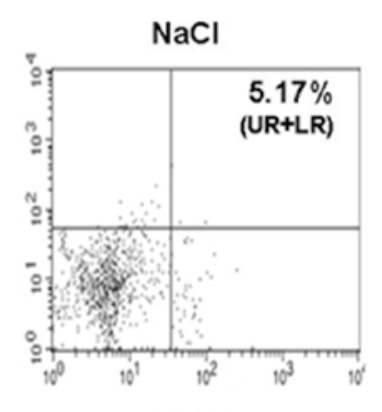

LPS

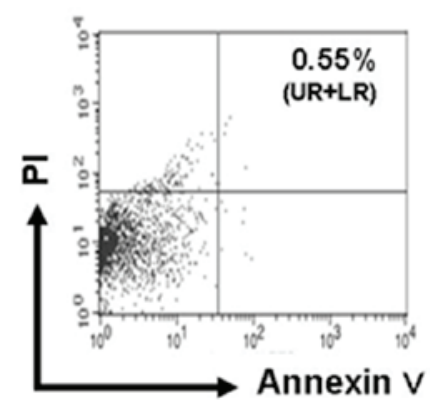

B
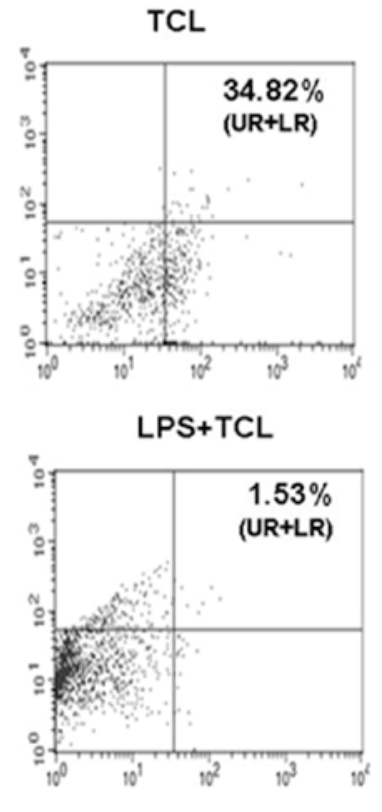

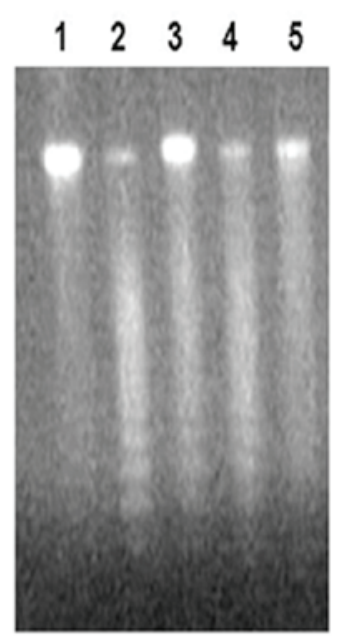

Figure 3. TCL induces the apoptosis of mouse splenocytes. Mouse splenocytes were cultured for $48 \mathrm{~h}$ in a medium containing $0.85 \%$ NaCl, TCL from Lewis lung cancer cells, MHSP65, LPS alone or LPS + TCL. The level of apoptosis in slpenocytes was determined by flow cytometry or DNA ladder. (A) The numbers in each plot image represent the positive percentage of Annexin V (UR percentage + LR percentage). Representative data from one of the three experiments are shown. (B) Genomic DNA of mouse splenocytes cultured with medium containing $0.85 \%$ NaCl (Lane 5), TCL from Lewis lung cancer cells (Lane 2), MHSP65 (Lane 4), LPS alone (Lane 1) or LPS + TCL (Lane 3) was analyzed by agar-gel. The ladder degraded bands of genome DNA indicate apoptosis of splenocytes. MHSP65, mycobacterial heat shock protein 65; LPS, lipopolysaccharide; TCL tumor cell lysate; PI, propidium iodide; NaCl, sodium chloride; UR, upper right; LR, lower right.

following incubation with LPS for $48 \mathrm{~h}$. If the mouse splenocytes were simultaneously treated with TCL and LPS, their apoptotic rate increased to $1.53 \%$ ( $\mathrm{P}<0.05$ vs. LPS group). A DNA ladder assay also revealed that TCL was able to promote the apoptosis of mouse splenocytes. In the TCL-treated mouse splenocytes, electrophoresis of the genomic DNA revealed evident DNA ladders. In the $\mathrm{NaCl}$ group and the LPS group, electrophoresis of the genomic DNA failed to show any DNA ladders. However, following simultaneous treatment with LPS and TCL, electrophoresis of the genomic DNA from the mouse splenocytes again demonstrated DNA ladders (Fig. 3B).

TCL from Lewis cells upregulates CD69 expression in mouse splenic lymphocytes and induces production of Treg cells. The transformation of $\mathrm{CD}^{+} \mathrm{T}$ cells into Treg cells is an inducer of tolerance to tumor vaccination (20). In order to investigate whether TCL-induced tolerance to tumor vaccines is associated with Treg cells, mouse splenic lymphocytes were treated with TCL in vitro for $48 \mathrm{~h}$ and then flow cytometry was performed to detect the Treg cells (Fig. 4A). The results demonstrated that following TCL treatment, the proportion of Treg cells was $15.67 \%$ in the $\mathrm{CD}^{+}$ $\mathrm{T}$ lymphocytes. However, in the $\mathrm{NaCl}$ group, the proportion of Treg cells was $5.70 \%(\mathrm{P}<0.05)$. Notably, in the LPS-treated $\mathrm{CD}^{+} \mathrm{T}$ lymphocytes, the proportion of Treg cells was $8.30 \%$ and in the $\mathrm{CD}^{+} \mathrm{T}$ lymphocytes treated with LPS and TCL, the proportion of Treg cells was $8.63 \%$, suggesting that the number of Treg cells was not significantly increased $(\mathrm{P}>0.05$ vs. LPS group). Treg cells are a group of immunosuppressive
$\mathrm{CD}^{+} \mathrm{T}$ lymphocytes. The production of Treg cells is associated with CD69 expression and TGF- $\beta$ secretion in immune cells (21). Consistently, after $48 \mathrm{~h}$ treatment with TCL, the expression of CD69 was significantly increased in the mouse splenic lymphocytes with CD69 expressed in $23.41 \%$ of the splenic lymphocytes (Fig. 4B). However, in the $\mathrm{NaCl}$ group, CD69 expression was observed only in $8.55 \%$ of the splenic lymphocytes $(\mathrm{P}<0.01)$.

\section{Discussion}

TCL has long been used as a stimulator of immune cells and as an antitumor vaccine. However, there are substances in TCL that can exert an immunosuppressive effect and induce apoptosis, resulting in adverse effects on the action of TCL. Thus, it is imperative to detect these substances and to investigate the mechanisms underlying the effect of these substances on TCL-mediated immunoactivation $(22,23)$. In our previous studies, TCL was prepared from Lewis lung cancer cells and the results demonstrated that the use of TCL could induce antitumor immunity that was not maintained during the late phase (2). It was hypothesized that this may be attributed to certain components in the TCL that could inhibit immune cells. In the present study, the results demonstrated the presence of HA in the TCL from Lewis lung cancer cells and it has been confirmed that HA is closely associated with the production of immunosuppressive immune cells (M $\Phi$ and DC). The concentration of HA was $42 \mathrm{mg} / \mathrm{ml}$ in the TCL from the Lewis lung cancer cells $\left(1 \times 10^{6}\right)$. In prior animal studies, the animals were immunized at several time points and thus, the in vivo HA 
A
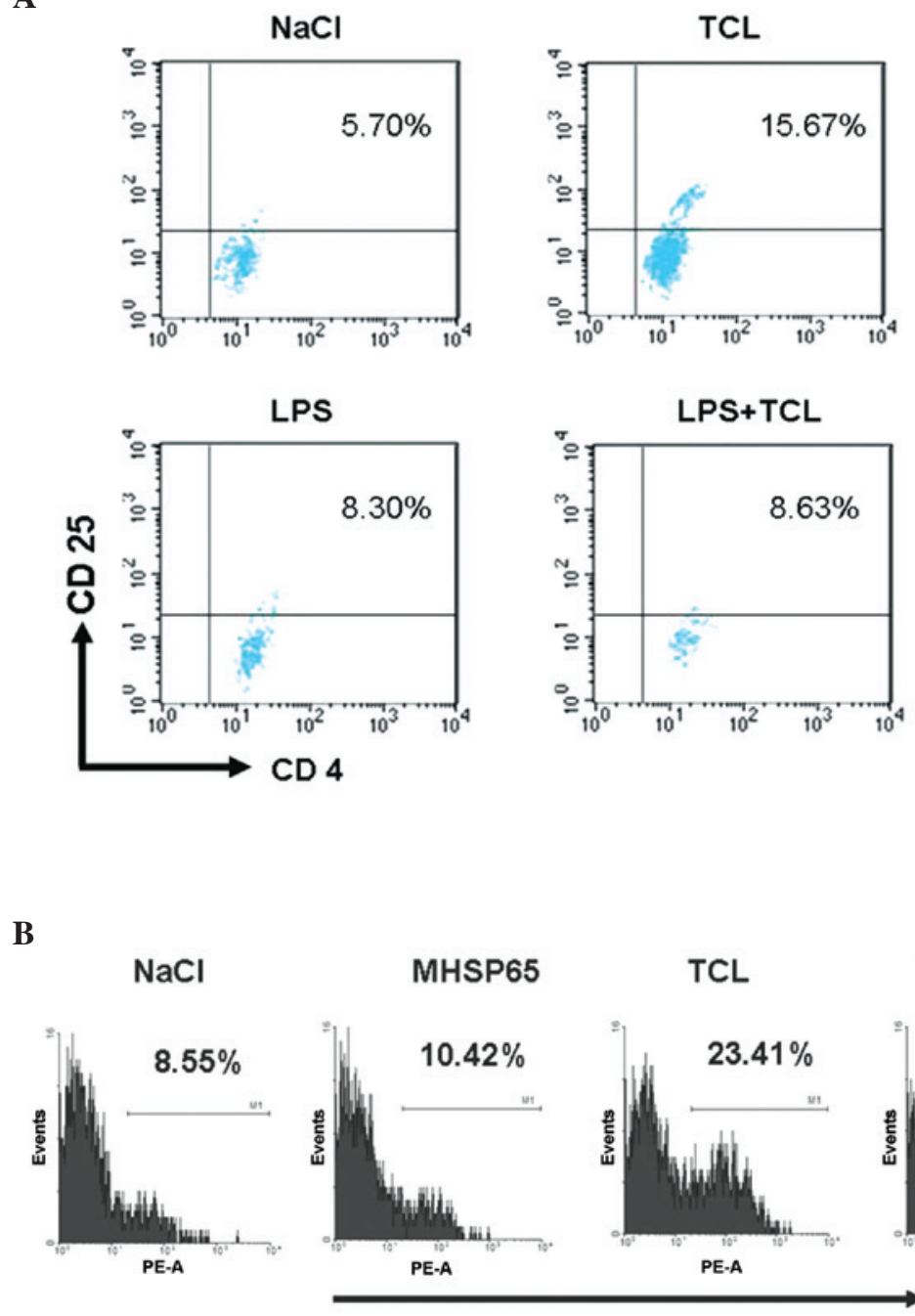

MHSP65+TCL

CD 69

Figure 4. TCL upregulates the expression of CD69 and induces the formation of Tregs. (A) Mouse splenocytes were cultured for $48 \mathrm{~h}$ in medium containing $0.85 \% \mathrm{NaCl}$, TCL from Lewis lung cancer cells, LPS alone or LPS with TCL (LPS + TCL). The expression levels of CD4 and CD25 were determined by flow cytometry. The number in each upper right quadrant is the percentage of CD4/CD25 double-positive $\mathrm{T}$ cells. Representative data from one of the three experiments are shown. (B) Mouse splenocytes were cultured for $48 \mathrm{~h}$ in medium containing $0.85 \% \mathrm{NaCl}$, TCL from Lewis lung cancer cells, MHSP65 alone or MHSP65 with TCL (MHSP65 + TCL). The expression of CD69 was determined by flow cytometry. The number in each histogram represents the CD69 mean fluorescence intensity of the sample. Tregs, regulatory T cells; $\mathrm{NaCl}$, sodium chloride; TCL, tumor cell lysate; MHSP65, mycobacterial heat shock protein 65; LPS, lipopolysaccharide.

concentration may be higher. At this concentration, HA was able to induce the production of immunosuppressive cells (24). The TCL-treated MФs were consistently found to possess an elevated capability to secrete TNF- $\alpha$ and the secretion of TNF- $\alpha$ decreased over time. However, the secretion of IL-10 gradually and continuously increased. In the $\mathrm{NaCl}$-treated MФs, the secretion of TNF- $\alpha$ and IL-10 demonstrated an opposite tendency to that of the TCL-treated MФs. Similar findings in the secretion of TNF- $\alpha$ and IL-10 by mouse DCs were also demonstrated following TCL or $\mathrm{NaCl}$ treatment. These findings suggest that following TCL treatment, the MФs and DCs transform into a special group of immunosuppressive MФs. The immunosuppressive MФs and DCs are characterized by a reduction in the secretion of TNF- $\alpha$ and IL-12 and an increase in the secretion of IL-10, an inhibitory cytokine (25). These immunosuppressive MФs and DCs may be derived from immature mouse MФs and DCs following incubation with the HA in the TCL. If immunosuppressive MФs and DCs are present, they may secrete a large quantity of IL-10 to induce the apoptosis of T lymphocytes. In addition, immunosuppressive MФs and DCs are also susceptible to a secondary apoptosis following transient activation, which may result in a reduction in the proportion of antigen-presenting cells in the immune cells and may affect TCL-activated antitumor immune cells $(4,26)$.

In addition to HA, two pro-apoptotic factors (Fas-L and TGF- $\beta$ ) were also detected in the TCL. In the TCL from Lewis lung cancer cells $\left(1 \times 10^{6}\right)$, the concentration of Fas- $\mathrm{L}$ and TGF- $\beta$ was $200 \mathrm{ng} / \mathrm{ml}$ and $239.64 \mathrm{pg} / \mathrm{ml}$, respectively. The two proteins may assist cancer cells in escaping antitumor immunity. Fas-L may bind to Fas on the immune cells to trigger a cysteine protease cascade to induce the apoptosis of antitumor immune cells and thus, these immune cells fail to exert an antitumor effect (27). TGF- $\beta$ is a multifunctional 
cytokine that can be secreted by cancer cells and at the same time, act on themselves by exerting an antitumor effect. If there is TGF- $\beta$ in the TCL, the TGF- $\beta$ may act on the immune cells to inhibit their function or even induce the apoptosis of these immune cells. Thus, TGF- $\beta$ assists cancer cells in evading the antitumor immunity and promotes cancer formation (28). In the present study, TCL was directly used to treat mouse splenocytes over $48 \mathrm{~h}$ and the apoptosis of these cells was observed (apoptotic rate: $34.82 \%$ ). This may be attributed to the direct contact between the splenocytes and Fas-L/TGF- $\beta$ in the TCL. The ability of TCL to induce cell apoptosis is potent and, as a potent immune activator, LPS fails to completely inhibit this effect. Thus, although there are cancer antigens in the TCL, which could activate immune cells as LPS does, other factors, including Fas-L and TGF- $\beta$, may also induce the apoptosis of immune cells (apoptotic rate of mouse splenocytes: $34.82 \%$ ). This undoubtedly affects TCL-mediated antitumor immunity.

The apoptosis of immune cells is associated with not only the pro-apoptotic factors, but also with the upregulation of the expression of CD69 on these cells (29). If the expression of CD69 on T lymphocytes and natural killer NK cells increases, the CD69 cells may activate secondary messengers and protein kinases, including $\mathrm{Ca}^{2+}$ and protein kinase $\mathrm{C}$, which further activate signaling pathways resulting in increased secretion of TGF- $\beta$ by the T lymphocytes and NK cells. TGF- $\beta$ acts on immune cells to induce their apoptosis (30). In our previous study and in the present study, the results demonstrated that CD69 expression in the mouse splenic lymphocytes significantly increased following treatment with TCL and the proportion of CD69 positive cells was $23.41 \%$. Of note, of the TCL-treated mouse splenic lymphocytes, $\mathrm{CD} 4^{+} / \mathrm{CD} 25^{+}$Treg cells were detectable. Treg cells are a group of $\mathrm{CD} 4^{+} \mathrm{T}$ lymphocytes with immunosuppressive capability and can inhibit the activation of certain immune cells, including $\mathrm{CD}^{+}$cells, $\mathrm{CD}^{+} \mathrm{T}$ cells, NK cells and monocytes (31). In addition, the inhibitory activity of Treg cells is associated with the excessive expression of CD69 on them (32). In our previous study, CD69 was used as a marker for the activation of immune cells (21). Cancer antigens in the TCL could effectively activate immune cells that were characterized by an increase in the expression of CD69 on these cells (33). However, although CD69 may be used as a marker for immune cell activation, the expression of CD69 is not involved in the activation of immune cells and the occurrence of antitumor immunity (34). CD69 ${ }^{-/-}$mice were found to have a more potent antitumor capability (35). If an anti-CD69 antibody was used to inhibit CD69 expression, an antitumor effect was observed in cancer-bearing mice, suggesting the antitumor effect of the CD69 antibody (30). Thus, as for the detection of immune activators in the TCL, other cellular surface molecules, including HLA-DR and CD38, may be used (36). In addition, inhibition of the expression of CD69 assists in increasing the immunocompetence of the TCL.

Taken together, the results of the present study demonstrated that HA, Fas-L and TGF- $\beta$ were present in the TCL from Lewis lung cancer cells, and may induce the production of immunosuppressive MФs and DCs, or directly induce the apoptosis of immune cells. These molecules may significantly compromise the immunocompetence of TCL or cause a non-response to TCL. In addition, TCL may activate CD69 expression, leading to the production of Treg cells, which may further increase immune cell inhibition and apoptosis, and thus further reduce the antitumor activity of the TCL. On the basis of the abovementioned findings, removal of HA, Fas-L and TGF- $\beta$ from the TCL preparation and inhibition of CD69 expression may improve the antitumor activity of TCL.

\section{Acknowledgements}

This study was supported by the Anhui Provincial Natural Science Foundation (no. 1208085QC49), the Anhui Provincial Natural Science Research Subject of Provincial University (no. KJ2012B200) and the Doctor Research Foundation of Wan Nan Medical College (no. 201215).

\section{References}

1. Yang DH, Park JS, Jin CJ, et al: The dysfunction and abnormal signaling pathway of dendritic cells loaded by tumor antigen can be overcome by neutralizing VEGF in multiple myeloma. Leuk Res 33: 665-670, 2009.

2. Dong B, Sun L, Wu X, et al: Vaccination with TCL plus MHSP65 induces anti-lung cancer immunity in mice. Cancer Immunol Immunother 59: 899-908, 2010.

3. Kuang DM, Zhao Q, Xu J, Yun JP, Wu C and Zheng L: Tumor-educated tolerogenic dendritic cells induce CD3 down-regulation and apoptosis of $\mathrm{T}$ cells through oxygen-dependent pathways. J Immunol 181: 3089-3098, 2008.

4. Kuang DM, Wu Y, Chen N, Cheng J, Zhuang SM and Zheng L: Tumor-derived hyaluronan induces formation of immunosuppressive macrophages through transient early activation of monocytes. Blood 110: 587-595, 2007.

5. Li H, Zhu H, Xu CJ and Yuan J: Cleavage of BID by caspase 8 mediates the mitochondrial damage in the Fas pathway of apoptosis. Cell 94: 491-501, 1998.

6. Chuster N and Krieglstein K: Mechanisms of TGF-beta-mediated apoptosis. Cell Tissue Res 307: 1-14, 2002.

7. Niehans GA, Brunner T, et al: Human lung carcinomas express Fas ligand. Cancer Res 57: 1007-1012, 1997.

8. Gutierrez LS, Eliza M, Niven-Fairchild T, Naftolin F and Mor G: The Fas/Fas-ligand system: a mechanism for immune evasion in human breast carcinomas. Breast Cancer Res Treat 54: 245-253, 1999.

9. Saji H, Nakamura H, Awut H, et al: Significance of expression of TGF- $\beta$ in pulmonary metastasis in non-small cell lung cancer tissues. Ann Thorac Cardiovasc Surg 9: 295-300, 2003.

10. Imai K, Minamiya Y, Goto A, et al: Bronchioloalveolar invasion in non-small cell lung cancer is associated with expression of transforming growth factor- $\beta 1$. World J Surg Oncol 11: 113 , 2013.

11. Kim HR, Wheeler MA, Wilson CM, et al: Hyaluronan facilitates invasion of colon carcinoma cells in vitro via interaction with CD44. Cancer Res 64: 4569-4576, 2004.

12. Anttila MA, Tammi RH, Tammi MI, Syrjanen KJ, Saarikoski SV and Kosma VM: High levels of stromal hyaluronan predict poor disease outcome in epithelial ovarian cancer. Cancer Res 60: $150-155,2000$

13. Auvinen P, Tammi R, Parkkinen J, et al: Hyaluronan in peritumoral stroma and malignant cells associates with breast cancer spreading and predicts survival. Am J Pathol 156: 529-536, 2000.

14. Subramanian G, Schwarz RE and Higgins L: Targeting endogenous transforming growth factor beta receptor signaling in SMAD4-deficient pancreatic carcinoma cells inhibits their invasive phenotypel. Cancer Res 64: 5200-5211, 2004.

15. Grimm M, Gasser M, Bueter M, et al: Evaluation of immunological escape mechanisms in a mouse model of colorectal liver metastases. BMC Cancer 10: 82, 2010.

16. Jansen T, Tyler B, Mankowski J L, et al: FasL gene knock-down therapy enhances the antiglioma immune response. Neuro Oncol 12: 482-489, 2010.

17. Hahne M, Rimoldi D, Schroter M, et al: Melanoma cell expressing of Fas (Apo1-1/CD95) ligand: implications for tumor immune escape. Science 274: 1363-1366, 1996.

18. Haidong D, Scott ES, Diva RS, et al: Tumor-associated B7-H1 promotes T-cell apoptosis: a potential mechanism of immune evasion. Nature Med 8: 793-800, 2002. 
19. Quesnel B: Tumor dormancy and immunoescape. APMIS 116 685-694, 2008

20. Attia P, Powell DJ Jr, Maker AV, Kreitman RJ, Pastan I and Rosenberg SA: Selective elimination of human regulatory $\mathrm{T}$ lymphocytes in vitro with the recombinant immunotoxin LMB-2. J Immunother 29: 208-214, 2006.

21. Radstake TR, van Bon L, Broen J, et al: Increased frequency and compromised function of $\mathrm{T}$ regulatory cells in systemic sclerosis (SSc) is related to a diminished CD69 and TGFb expression. PLoS One 4: e5981, 2009.

22. Chiang CL, Benencia F and Coukos G: Whole tumor antigen vaccines. Semin Immunol 22: 132-143, 2010.

23. Kawahara $\mathrm{M}$ and Takaku H: Intradermal immunization with combined baculovirus and tumor cell lysate induces effective antitumor immunity in mice. Int J Oncol 43: 2023-2030, 2013.

24. Mytar B, Woloszyn M, Szatanek R, et al: Tumor cell-induced deactivation of human monocytes. J Leukoc Biol 74: 1094-1101, 2003.

25. Mantovani A, Sozzani S, Locati M, Allavena P and Sica A: Macrophage polarization: tumor-associated macrophages as a paradigm for polarized M2 mononuclear phagocytes. Trends Immunol 23: 549-555, 2002.

26. Kryczek I, Wei S, Zou L, et al: Cutting edge: induction of B7-H4 on APCs through IL-10: novel suppressive mode for regulatory T cells. J Immunol 177: 40-44, 2006.

27. Bennett MW, O'connell J, O'sullivan GC, et al: Expression of Fas ligand by human gastric adenocarcinomas: a potential mechanism of immune escape in stomach cancer. Gut 44: 156-162, 1999.

28. Derynck R, Akhurst RJ and Balmain A: TGF-beta signaling in tumor suppression and cancer progression. Nat Genet 29: 117-129, 2001.
29. Pajusto M, Ihalainen N, Pelkonen J, et al: Human in vivo activated $\left.\mathrm{CD} 45 \mathrm{RO}^{+}\right) \mathrm{CD}\left(^{+}\right) \mathrm{T}$ cells are susceptible to spontaneous apoptosis that can be inhibited by the chemokine CXCL12 and IL-2, -6. -7 and -15. Eur J Immunol 34: 2771-2780, 2004.

30. Esplugues E, Vega-Ramos J, Cartoixa D, et al: Induction of tumor NK-cell immunity by anti-CD69 antibody therapy. Blood 105: 4399-4406, 2005.

31. Ralainirina N, Poli A, Michel T, Poos L, Andrès E, Hentges F and Zimmer J: Control of NK cell functions by CD4+CD25+ regulatory T cells. J Leukoc Biol 81: 144-153, 2007.

32. Radosavljević GD, Jovanović IP, Kanjevac TV and Arsenijević NN: The role of regulatory T cells in the modulation of anti-tumor immune response. Srp Arh Celok Lek 141: 262-267, 2013 (In Serbian).

33. David S, Manuel G and Francisco SM: CD69 is an immunoregulatory molecule induced following activation. Trends Immunol 26: 136-140, 2005.

34. Freedman RS, Kudelka AP, Kavanagh JJ, et al: Clinical and biological effects of intraperitoneal injections of recombinant interferongamma and recombinant interleukin 2 with or without tumor-infiltrating lymphocytes in patients with ovarian or peritoneal carcinoma. Clin Cancer Res 6: 2268-2278, 2000.

35. Esplugues E, Sancho D, Vega-Ramos J, et al: Enhanced antitumor immunity in mice deficient in CD69. J Exp Med 197: 1093-1106, 2003.

36. Schwenk R, Banania G, Epstein J, et al: Ex vivo tetramer staining and cell surface phenotyping for early activation markers CD38 and HLA-DR to enumerate and characterize malaria antigen-specific $\mathrm{CD} 8^{+} \mathrm{T}$-cells induced in human volunteers immunized with a Plasmodium falciparum adenovirus-vectored malaria vaccine expressing AMA1. Malar J 12: 376, 2013. 